\title{
O comportamento de curto prazo da volatilidade de commodities agrícolas brasileiras em relação ao mundo: uma aplicação do modelo VAR
}

\begin{abstract}
A atividade agropecuária está sujeita a diversas mudanças que variam desde as climáticas, os efeitos políticos, as pestes e doenças e; também; os efeitos financeiros e econômicos. No que tange aos últimos, podem-se elencar como sendo agentes mudanças governamentais, estrutura de preços, relação oferta/demanda e sazonalidade de preços. Diante desse contexto, o objetivo deste trabalho foi o de analisar o comportamento de curto prazo da volatilidade presente nas commodities açúcar, café, farelo de soja, óleo de soja brasileira frente ao mundo, e vice-versa com o intuito de investigar se as alterações de preços de cada uma destas commodities estão relacionadas com as variações mundiais e brasileiras. A fim de atingir este objetivo, o estudo fez uso dos modelos GARCH, GJR e EGARCH para determinar qual destes se ajustava melhor ao modelo. Para determinar o comportamento de curto prazo, o estudo fez uso do modelo de vetores autorregressivos (VAR) nas commodities par a par. Observou-se que, para o mercado mundial, a commodity que tem maior volatilidade associada é o café, e no Brasil, o modelo de vetores autorregressivos (VAR) nas commodities par a par. Observou-se que, para o mercado mundial, a commodity que tem maior volatilidade associada é o café, e no Brasil, o açúcar. Sob o prisma do comportamento de curto prazo das volatilidades, observou-se que o açúcar é o mais sazonal, com influências de volatilidade em até 14 defasagens. Para o café e o a presença de volatilidade unidirecional, isto é, os mercados não têm relação entre si, o que indica que para estes dois últimos mercados, os riscos associados estão presentes apenas em seus mercados.
\end{abstract}

Palavras-chave: Vetores autorregressivos; Volatilidade; Commodities.

\section{The short-term behavior of the volatility of Brazilian agricultural commodities in relation to the world: an application of the VAR model}

\begin{abstract}
Agricultural activity is subject to several changes ranging from climatic, political effects, pests and diseases and; too; financial and economic effects. With regard to the latter, governmental changes, price structure, supply/demand ratio and price seasonality can be listed as agents. Given this context, the objective of this work was to analyze the short-term behavior of volatility present in the commodities sugar, coffee, soybean meal, Brazilian soybean oil vis-à-vis the world, and vice versa in order to investigate whether the changes prices for each of these commodities are related to world and Brazilian variations. In order to achieve this objective, the study made use of the GARCH, GJR and EGARCH models to determine which of these fitted the model better. To determine short-term behavior, the study used the autoregressive vector model (VAR) in commodities pair by pair. It was observed that, for the world market, the com volatilityinflencesin For soybean oil and soybeans, unidirectional volatility was observed, that is, the markets are not related to each other, which indicates that for these last two markets, the associated risks are present only in their markets.
\end{abstract}

Keywords: Autoregressive vectors; Volatility; Commodities.

Topic: Finanças Empresariais

Received: 08/06/2020

Approved: 29/07/2020

Reviewed anonymously in the process of blind peer.

Bruno Pereira Conte (iD)

Universidade Franciscana, Brasil

http://lattes.cnpq.br/6967382475867011

http://orcid.org/0000-0002-3709-1749

b.conte@ufn.edu.br

Daniel Arruda Coronel

Universidade Federal de Santa Maria, Brasil

http://lattes.cnpq.br/9265604274170933

http://orcid.org/0000-0003-0264-6502

daniel.coronel@uol.com.br

Alberto Granzotto (id

Universidade Federal de Santa Maria, Brasil

http://lattes.cnpq.br/0783361789844596

http://orcid.org/0000-0001-6973-385X

betorg@ymail.com

DOI: 10.6008/CBPC2179-684X.2020.003.0002
Ismael Alan Halberstadt (iD

Universidade Federal de Santa Maria, Brasil

http://lattes.cnpq.br/8354968883542342

http://orcid.org/0000-0002-5418-3995

ismaah@hotmail.com

Luciano Amaral (iD

Universidade Federal de Santa Maria, Brasil

http://lattes.cnpq.br/0337516564129671

http://orcid.org/0000-0001-5734-2448

lucianoaml@gmail.com

Referencing this:

CONTE, B. P.; CORONEL, D. A.; GRANZOTTO, A.; HALBERSTADT, I. A.; AMARAL, L.. O comportamento de curto prazo da volatilidade de commodities agrícolas brasileiras em relação ao mundo: uma aplicação do modelo VAR. Revista Brasileira de Administração Científica, v.11, n.3, p.15-33, 2020. DOI:

http://doi.org/10.6008/CBPC2179-684X.2020.003.0002 


\section{INTRODUÇÃO}

A atividade agropecuária está sujeita a diversas mudanças que variam desde as climáticas, os efeitos políticos, as pestes e doenças e, também, os efeitos financeiros e econômicos. No que tange aos últimos, podem-se elencar como sendo agentes mudanças governamentais, estrutura de preços, relação oferta/demanda e sazonalidade de preços.

A atividade agropecuária gera como insumo, na sua maior parte as chamadas commodities, que são os produtos de origem primária transacionados nas bolsas de mercadorias. São normalmente produtos em estado bruto ou com pequeno grau de industrialização, com qualidade quase uniforme e produzidos e comercializados em grandes quantidades do ponto de vista global.

A grande importância atribuída a commodities na economia se deve ao fato de que podem ser uma forma de investimento, uma opção entre as tantas opções de aplicação no mercado, como poupança ou Fundos de Investimento. Assim as possíveis oscilações nas cotações desses produtos no mercado internacional podem causar perdas a agentes econômicos que os transacionam (BRANCO, 2008).

Segundo o referido autor, as principais commodities negociadas atualmente no mundo são: café, trigo, soja, milho, algodão, açúcar, álcool, boi, ouro, prata, cobre, aço e petróleo, dólar, euro, ações de grandes empresas, títulos de governos nacionais. As principais commodities negociadas pelo Brasil, e compostas no Índice de Commodities Brasil da Bolsa de Mercadorias e Valores de São Paulo (BM\&F Bovespa) são: açúcar, boi gordo, café, soja e etanol hidratado (BOVESPA, 2014).

Sabendo da importância das commodities no mercado financeiro, pressupõe-se que estas sejam alvos de alta procura no mercado, o que gera alterações constantes nos preços. Estas modificações constantes acarretam a volatilidade destes preços. Segundo Swaray (2002), a origem da volatilidade é diferente de acordo como grupo de commodity. No caso das commodities agrícolas, a volatilidade origina-se, principalmente, de distúrbios da oferta. As flutuações de demanda, de um ano para outro, por exemplo, sofrem somente modificações moderadas, ao passo que a oferta flutua consideravelmente, de acordo com variáveis climáticas e técnicas da cultura, além das expectativas e dos movimentos especulativos. Assim, esses distúrbios, combinados com a elasticidade de oferta e demanda de curto prazo, ocasionam flutuações de preços acentuadas (PEREIRA et al., 2010)

Mesmo com estas mudanças, os países procuram explorar a atividade agropecuária, pois esta tem tido grande participação na pauta das balanças comerciais, o que gera um balanço positivo a quem participa deste mercado. O Brasil tem uma crescente participação no mercado internacional, resultado da combinação de importantes fatores tais como o clima propício, o investimento em tecnologia, a disponibilidade de terras agricultáveis férteis e de alta produtividade, além do aproveitamento da mesma área para diversificar a produção.

Considerando as principais commodities negociadas no Brasil e no mundo, avaliando a participação crescente do país no mercado financeiro de commodities e considerando que a diferença de oferta e demanda neste mercado acarreta modificações nos preços, o objetivo deste trabalho consiste em avaliar a 
relação de curto prazo que a volatilidade das commodities brasileiras possam ter com o mundo, e vice-versa.

Para o alcance do objetivo proposto, este trabalho fará uso do modelo de Vetores Autorregressivos (VAR); para determinar a relação de curto prazo existente nos riscos das commodities brasileiras em relação às mundiais. Foram selecionadas cinco das principais commodites para este estudo - açúcar, café arábica, farelo de soja, óleo de soja e soja em grão- e foram coletados os preços à vista destas, tanto do Brasil quanto do agregado mundial.

A relevância dispensada a este estudo reside na avaliação do risco das commodities. Deve-se destacar que as flutuações de preços podem inviabilizar todo o processo produtivo, visto que uma queda na remuneração pelo produto pode tornar os resultados do negócio negativos, mesmo em situações de eficiência produtiva e produtividade elevada. Portanto, a mensuração do risco, como a variabilidade dos retornos, é uma variável importante para a tomada de decisão dos produtores, além de ser uma informaçãochave para os especuladores e hedgers.

O presente artigo está estruturado, além desta introdução em quatro seções. Na segundo seção é apresentado o referencial teórico, que traz considerações acerca das commodities agrícolas brasileiras e a volatilidade. Na terceira seção são apresentados os testes estatísticos e os modelos econométricos utilizados. A quarta seção apresenta os resultados do trabalho. A quinta seção é destinada às considerações finais e à conclusão do estudo.

\section{REVISÃO TEÓRICA}

\section{As commodities agrícolas brasileiras}

As commodities são responsáveis por mais de $70 \%$ das receitas de exportação do Brasil, e a conjugação de forte aumento de seus preços com significativa expansão das quantidades exportadas, como resultado natural, gera elevação dupla das receitas de exportação. O mercado brasileiro de commodities é bastante diversificado, sendo farto desde commodities agrícolas até os minerais e financeiras. Para este estudo, serão conceituadas as commodities agrícolas açúcares, café arábica e o complexo soja, composto do farelo de soja, do óleo de soja e da soja em grão, que compõem cerca de $60 \%$ do total exportado pelo país.

Segundo dados da Confederação da Agricultura e Pecuária do Brasil (CNA), as culturas da soja e do café representaram, ao longo de 2008, 17,7\% e 5,0\% do valor bruto da produção agropecuária brasileira. Considerando o valor exportado, o café teve uma evolução gradativa entre os anos de 2008 e 2012, sempre com tendência de crescimento, conforme pode ser visualizado na Tabela 1.

Tabela 1: Evolução das quantidades exportadas por commodities - em 1.000 toneladas.

\begin{tabular}{llllll}
\hline Produtos & $\mathbf{2 0 0 8}$ & $\mathbf{2 0 0 9}$ & $\mathbf{2 0 1 0}$ & $\mathbf{2 0 1 1}$ & $\mathbf{2 0 1 2}$ \\
\hline Café & 1567 & 1639 & 1791 & 1791 & 1800 \\
Soja (grão) & 24499 & 28563 & 29073 & 32985 & 32500 \\
Soja (Farelo) & 12288 & 12253 & 13668 & 14355 & 15000 \\
Açúcar & 13624 & 17925 & 20939 & 20153 & 20000 \\
\hline
\end{tabular}

Já o complexo soja é aquele que maior percentual sobre as exportações de commodities brasileiras, chegando a cerca de 9,4\% do total exportado no ano de 2012. Nota-se também, a partir da Tabela 1, que a 
soja em grão tem valor bruto exportado maior que o farelo de soja. Este fato deve-se à procura, especialmente da China, pela soja em grão brasileira, sendo que cerca de $70 \%$ da produção total do país e destinada à China.

O óleo de soja é produzido em maior quantidade na cidade de São Paulo e sua produção respondeu, em média, por $4,13 \%$ do total de dispêndio de uma família média nessa cidade. Outro aspecto relevante consiste no fato de que o óleo de soja corresponde a $87,1 \%$ do total de óleos consumidos, sendo que os restantes $12,9 \%$ envolvem os demais tipos de óleos vegetais, como o de milho, de algodão, de canola, de girassol (MARGARIDO et al., 2004).

Considerando o mercado do açúcar, o valor gerado das exportações somou US\$ 500,23 milhões em 2009 , sendo 39,54\% superior ao do ano anterior. Em comparação com as exportações de janeiro/2010, houve uma diminuição de 30,51\% do volume de açúcar destinado ao mercado externo (CEPEA, 2012). O consumo interno de açúcar não apresenta aumento expressivo, apenas cresce a uma taxa parecida com a da população brasileira, pouco menos de $2 \%$ ao ano. Já o mercado mundial apresenta tendência de crescimento do consumo em países em desenvolvimento, ao contrário do que acontece nos países já desenvolvidos (TEIXEIRA, 2014).

Analisando os mercados propostos, nota-se que estes são, de fato, produtos importantes para a balança comercial brasileira e sua análise se faz pertinente. Nota-se que o complexo soja é o que tem maior representatividade bruta nas exportações, enquanto o açúcar e o café são produtos tradicionais, já presentes nas pautas de exportações do Brasil há mais tempo.

\section{Volatilidade}

Produção e preço de commodities são variáveis naturalmente atreladas. Por um lado, o nível de preços pode interferir nas decisões de produção e investimento dos produtores, por meio da geração de expectativas otimistas ou pessimistas. Por outro lado, os preços são definidos pela produção, uma vez que o cruzamento da oferta disponível com a demanda é responsável por determinar o preço (PEREIRA et al., 2010). Com essa relação, os ciclos produtivos possuem significativo efeito sobre a definição dos valores pagos pelos produtos agrícolas. Nesse sentido, café e açúcar destacam-se por apresentarem ciclos produtivos marcados por mais flutuações; consequentemente, os preços caracterizam-se por maior volatilidade.

Assim, espera-se que a volatilidade dos preços do açúcar e do café sejam menores em relação ao do complexo soja. Seguindo esta temática, destacam-se alguns trabalhos empíricos que buscaram elucidar as relações de volatilidade de algumas commodities brasileiras, como o de Margarido et al. (2004), Silva et al. (2005), Campos (2007), Teixeira et al. (2008) e Pereira et al. (2010).

O trabalho de Margarido et al. (2004) analisou os efeitos que as variações na taxa de câmbio e os preços internacionais do grão de soja tem sobre a volatilidade do preço do óleo de soja, por meio dos modelos ARCH. Os autores verificaram que existe relação do óleo de soja nas taxas de câmbio. Silva et al. (2005) analisaram a volatilidade da soja e do café, por meio da modelagem da variância como um processo autorregressivo de heteroscedasticidade (ARCH). Com base nos preços mensais, entre janeiro de 1967 e abril 
de 2002, os autores identificaram expressiva persistência dos choques, para ambos os produtos.

Também com base nos modelos ARCH, Campos (2007) estudou a volatilidade dos retornos mensais da soja, do café, do milho e do boi gordo, entre janeiro de 1967 e julho de 2006. Como resultado, esse autor ratificou a existência de comportamento da variância dos preços dos produtos selecionados, de forma que a persistência dos choques ocorridos é maior sobre as cotações do boi gordo, seguido, respectivamente, pelo café, pela soja e pelo milho.

Os trabalhos de Teixeira et al. (2008) e Pereira et al. (2010) tiveram como foco analisar, comparativamente, os retornos privados de três commodities importantes para o agronegócio brasileiro. Os autores usaram os modelos autorregressivos com heteroscedasticidade (ARCH) e, para Pereira et al. (2010) agruparam à análise o Value-at-Risk (VaR), para o período entre os dias 30/07/1997 e 12/11/2008.

Ambos os autores concluíram que existe variabilidade dos retornos dos três produtos e possui dependência, além de as volatilidades dos retornos das commodities gerarem forte persistência para dissipar-se aos choques positivos e negativos. Considerando a literatura supracitada, o objetivo do trabalho é fazer uso dos modelos de volatilidade, como os GARCH, EGARCH e GJR nas commodities par a par, isto é, verificar relacionamentos de curto prazo existentes entre as commodities brasileiras e mundiais, com o objetivo de identificar seu relacionamento.

Ademais, optou-se por usar os dados de preços mensais, com vista a diminuir o efeito variabilidade e estimar os modelos com maior precisão. O horizonte temporal deste estudo é de 1/1/1990 até 30/11/2013, o que correspondeu a 287 observações de cada commodity. Os dados estão padronizados pelo preço por kg, em dólar. Os valores das commodities brasileiras foram deflacionados com base no IGP-DI.

\section{METODOLOGIA}

\section{Delineamento da pesquisa}

Este trabalho tem um enfoque quantitativo, visto que pretende medir o relacionamento de volatilidades. Esta pesquisa se caracteriza também por ser descritiva e exploratória. Segundo Gil (2010), as pesquisas descritivas têm o objetivo de apresentar características de determinada população ou fenômeno. Além disso, a pesquisa pode também ser considerada descritiva porque foram realizadas observações e análises a fim de registrar e correlacionar fenômenos (RAMPAZZO, 2002).

Também segundo Gil (2010), a pesquisa exploratória tem por objetivo o aprimoramento de ideias e levantamento de fatos. Com isso, o estudo é exploratório, pois tem o apoio de alguns outros estudos da literatura, fazendo um aprimoramento ou, analisando uma diferente problemática com métodos diferentes a fim de verificar a otimização das ideias.

\section{Modelo Empírico}

\section{Atribuição da Volatilidade}

Este estudo fará uso dos modelos de volatilidade não condicionais, que são as extensões dos modelos 
ARCH: GARCH, GJR e EGARCH. Uma generalização natural dos modelos ARCH foi proposta por Bollerslev (1986), e ficou conhecida como GARCH (General Autoregressive Conditional Heteroscedasticity). Como em muitas aplicações é requerido que o modelo $\mathrm{ARCH}$ apresente muitos lags (q), os modelos GARCH estendem a formulação $\mathrm{ARCH}$ no sentido de que aquele permite uma memória mais longa, e uma estrutura de defasagens para a variância mais flexível. Estes modelos também podem ser utilizados para entender a relação entre a volatilidade e os retornos esperados (MORAIS et al., 1999). O modelo passa a ser dado por

$$
\begin{gathered}
\varepsilon_{t} / \psi_{t-1} \sim N(0, h,) \\
h_{t}=\alpha_{0}+\sum_{i=1}^{q} \alpha_{i} \varepsilon_{t-1}^{2}+\sum_{i=1}^{p} \beta_{i} h_{t-i}=\alpha_{0}+A(L) \varepsilon_{t}{ }^{2}+B(L) h_{t} \\
\varepsilon_{t}=R_{t}-x_{t} b
\end{gathered}
$$

Onde as restrições são agora dadas por; $\mathrm{q}>0, \mathrm{p} \geq 0, \alpha_{0}>0, \alpha_{i} \geq 0$, (i=1,..,q), e $\beta_{i} \geq 0,(\mathrm{i}=1, \ldots, \mathrm{p})$. Se $\mathrm{p}=0$, o modelo se reduz a um $\mathrm{ARCH}(\mathrm{q})$ e se $\mathrm{p}=\mathrm{q}=0$, então $\varepsilon t$ é um ruído branco. Para que o processo seja bem definido, é requerido também que $\frac{h_{t}=\alpha(L) \varepsilon_{t}{ }^{2}}{1-\beta(L)}$ seja não negativo, e que as raízes do polinômio $\beta(\lambda)=1$ estejam fora do círculo unitário.

Uma outra especificação muito utilizada na literatura para captar o efeito assimetria (modelo GJR) foi proposta por Glosten et al. (1993) e pode ser descrita como

$$
\begin{gathered}
\varepsilon_{t / \psi t-1} \sim N(0, h,) \\
h_{T}=\omega+\beta h_{t-1}+\alpha \varepsilon_{t-1^{2}+\gamma S_{t-1}{ }^{-} \varepsilon_{t-1}{ }^{2}} \\
S_{t}^{-}=\quad \begin{array}{l}
1 \text { se }^{\varepsilon_{t}}<0 \\
0 \text { se } \varepsilon_{t} \geq 0
\end{array}
\end{gathered}
$$

Logo, quando g $>0$ captura-se o efeito leverage ${ }^{1}$ e com g $=0$ o modelo $\mathrm{GJR}(1,1)$ reduz-se a um $\mathrm{GARCH}(1,1)$. Neste sentido, o modelo GARCH é "aninhado" ao modelo GJR (MORAIS et al., 1999).

A correlação entre os preços das commodities e as mudanças na sua volatilidade pode ser negativa, pois são observados que grandes diferenças entre oferta e demanda aumentam a volatilidade, enquanto que a diminuição da diferença entre oferta e demanda a diminuem. Nelson (1991) propôs um modelo não-linear alternativo, o EGARCH que é da forma

$$
\begin{array}{r}
\varepsilon_{t} / \psi_{t-1} \sim N(0, h,) \\
h_{t}=\omega+\beta h_{t-1}+\alpha \varepsilon_{t-1}{ }^{2}+\gamma S_{t-1}{ }^{-} \varepsilon_{t-1}{ }^{2} \\
\varepsilon_{t}=R_{t}-x_{t} b \\
S_{t}^{-}=\quad \begin{array}{r}
1 \text { se }^{\varepsilon_{t}}<0 \\
0 \text { se } \varepsilon_{t} \geq 0
\end{array}
\end{array}
$$

Neste modelo, incluindo o choque padrão $(\varepsilon t-1)$ e o seu valor absoluto, é dada maior flexibilidade à equação da variância, permitindo que ela capture alguma assimetria na relação entre retornos de mercado e a volatilidade . O modelo é assimétrico devido à existência do coeficiente $\gamma$, que capta o efeito leverage.

\footnotetext{
${ }^{1}$ Efeito de assimetria de volatilidade, com alavancagem de valores (MORAIS et al., 1999).
} 


\section{Modelo de vetores autorregressivos}

A maioria dos fenômenos, sejam eles naturais ou econômicos, acontecem simultaneamente. Sendo assim, uma metodologia condizente com esta ótica leva em consideração duas ou mais séries, ou seja, é realizada uma análise multivariada e a relação dinâmica entre elas (LEROY et al., 2008).

Segundo Bueno (2008), em um modelo VAR, o vetor $y_{t} \in \mathfrak{R}^{n}$ no instante $t$ é descrito apenas por seus valores passados e pelo vetor de ruído branco $\varepsilon_{t} \in \mathfrak{R}^{n}$. O modelo VAR mais geral é o de ordem n, nele o vetor $y_{t}$ depende de $y_{t-1}, y_{t-2}, \ldots, y_{t-n}$ e do vetor de resíduos $\varepsilon_{t}$, que estão correlacionados entre eles no instante t mas não em momentos anteriores a t. A sua representação algébrica é a seguinte:

$$
y_{t}=\alpha+\sum_{k=1}^{p} A_{k} y_{t-k}+\varepsilon_{t}
$$

Onde $\alpha \in \mathfrak{R}^{n}$ é o vetor de intercepto, $A_{k} \in \mathfrak{R}^{n x n}, \mathrm{k}=0,1,2, \ldots, \mathrm{n}$, são as matrizes dos coeficientes do modelo, e $\varepsilon_{t} \in \mathfrak{R}^{n x n}$ é o vetor de resíduos, tal que: $E\left[\varepsilon_{t}\right]=0 \in \mathfrak{R}^{n x n}, E\left[\varepsilon_{t} \varepsilon_{t}{ }^{T}\right]=\sum \in \mathfrak{R}^{n x n}$.

Um dos maiores problemas encontrados no processo de modelos de vetores autorregressivos é a sua identificação. Uma maneira de identificar a ordem $\mathrm{n}$ de um modelo de vetores autorregressivos ( $\mathrm{n}$ ) consiste em ajustar sequencialmente modelos autorregressivos vetoriais de ordens $1,2, \ldots, k$ e testar a significância dos coeficientes (matrizes). Para identificar o modelo que melhor se ajusta à ordem dos vetores autorregressivos, será feito o teste de número de defasagens, que será descrito a seguir.

\section{Testes estatísticos}

\section{Teste de número de defasagens do modelo autorregressivo}

O teste de número de defasagens é um modelo de estimação ótima das defasagens previstas a serem ajustadas para os vetores autorregressivos. Segundo Ng et al. (2001), a identificação do melhor modelo pode ser por tentativa e Erro pelo modelo OLS, utilizar critérios de razão verossimilhanças e utilizar os critérios de Akaike, Schwarz e Hannan-Quinn. Este trabalho usou o critério de informação de Akaike, Schwarz e HannanQuinn, que tem a expressão algébrica descrita a seguir

$$
\begin{aligned}
& A I C(k)=\ln \left(\left|\hat{\sum} k\right|\right)+2 k n^{2} / T(\text { Akaike }) \\
& B I C(k)=\ln \left(\left|\hat{\sum} k\right|\right)+k n^{2} \ln (T) / T(\text { Schwarz }) \\
& \left.H Q C(k)=\left(\left|\hat{\sum} k\right|\right)+k n^{2} \ln (\ln (T)) / \text { T(Hannan-Quinn }\right)
\end{aligned}
$$

Os testes das Equações 5, 6 e 7 preveem que, quanto menor o valor do teste, melhor o modelo está ajustado. 


\section{Teste de raiz unitária}

O primeiro teste a ser feito é o da raiz unitária, pois se trata de uma cadeia temporal. Segundo Baltagi (2005), esses testes são cada vez mais encontrados nos estudos realizados com séries temporais. Segundo Fava et al. (1995), a origem da discussão sobre a existência de raiz unitária nas séries econômicas está no debate sobre a estacionariedade ou não da tendência, sendo que grande parte dos dados utilizados na análise empírica em economia é em forma de uma série temporal.

Sua expressão algébrica é demonstrada a seguir

$$
Y_{i t}=\rho Y_{i t-1}+X_{i t} \beta_{1}+\varepsilon_{i t}
$$

Onde $X_{i t}$ representa as variáveis exógenas do modelo, $\rho_{i}$ são os coeficientes autor- regressivos e $\varepsilon_{i t}$ é o termo de erro iid. Se $\left|\rho_{i}\right|<1, Y_{i}$ é dito fracamente exógeno e, se $\rho_{i}=1$, diz-se que a série tem raiz unitária.

Portanto, a determinação da presença de raiz unitária é relevante para a economia, porque auxilia no processo de verificação de várias teorias. Além disso, a presença de raiz unitária pode ser utilizada como um indicativo de que os agentes econômicos possuem um comportamento racional, utilizando todas as informações disponíveis (LEROY et al., 2008).

\section{RESULTADOS E DISCUSSÃO}

\section{Testes de raiz unitária e características das séries}

Inicialmente serão demonstrados os testes de raiz unitários, que são os procedimentos iniciais para a definição dos modelos de vetores autorregressivos, analisando cada variável separadamente. A tabela 2 a seguir demonstra os valores do teste de raiz unitários, sobre o critério de $5 \%$ de grau de confiança, com os valores de preço.

Tabela 2: Teste de raiz unitária para valores de preço.

\begin{tabular}{|c|c|c|c|}
\hline Variáveis & Nível de confiança & Estatística t & Prob.* \\
\hline Café arábica Brasil & & -2.583 & 0.288 \\
\hline Café arábica Mundo & & -2.339 & 0.160 \\
\hline Soja em grão Brasil & & -0.787 & 0.820 \\
\hline Soja em grão Mundo & & -2.719 & 0.229 \\
\hline Farelo de soja Brasil & & -3.591 & 0.032 \\
\hline Farelo de soja Mundo & & -2.377 & 0.390 \\
\hline Óleo de soja Brasil & & -3.332 & 0.063 \\
\hline Óleo de soja Mundo & & -2.758 & 0.214 \\
\hline Açúcar Brasil & & -1.941 & 0.629 \\
\hline Açúcar Mundo & & -3.155 & 0.095 \\
\hline
\end{tabular}

Analisando os resultados do teste de raiz unitária, nota-se que a maioria das séries de preços têm tendência determinística, e por esse motivo não são estacionárias, com exceção à série de preço do farelo de soja brasileiro, que apresenta estacionariedade a um grau de 5\%, porém não a 1\%. Analisando os gráficos das séries de preços (Figura 1), nota-se que em todos é notada a presença de tendência, o que indica que a série não seja estacionária, e sim, uma série de caminho aleatório. 

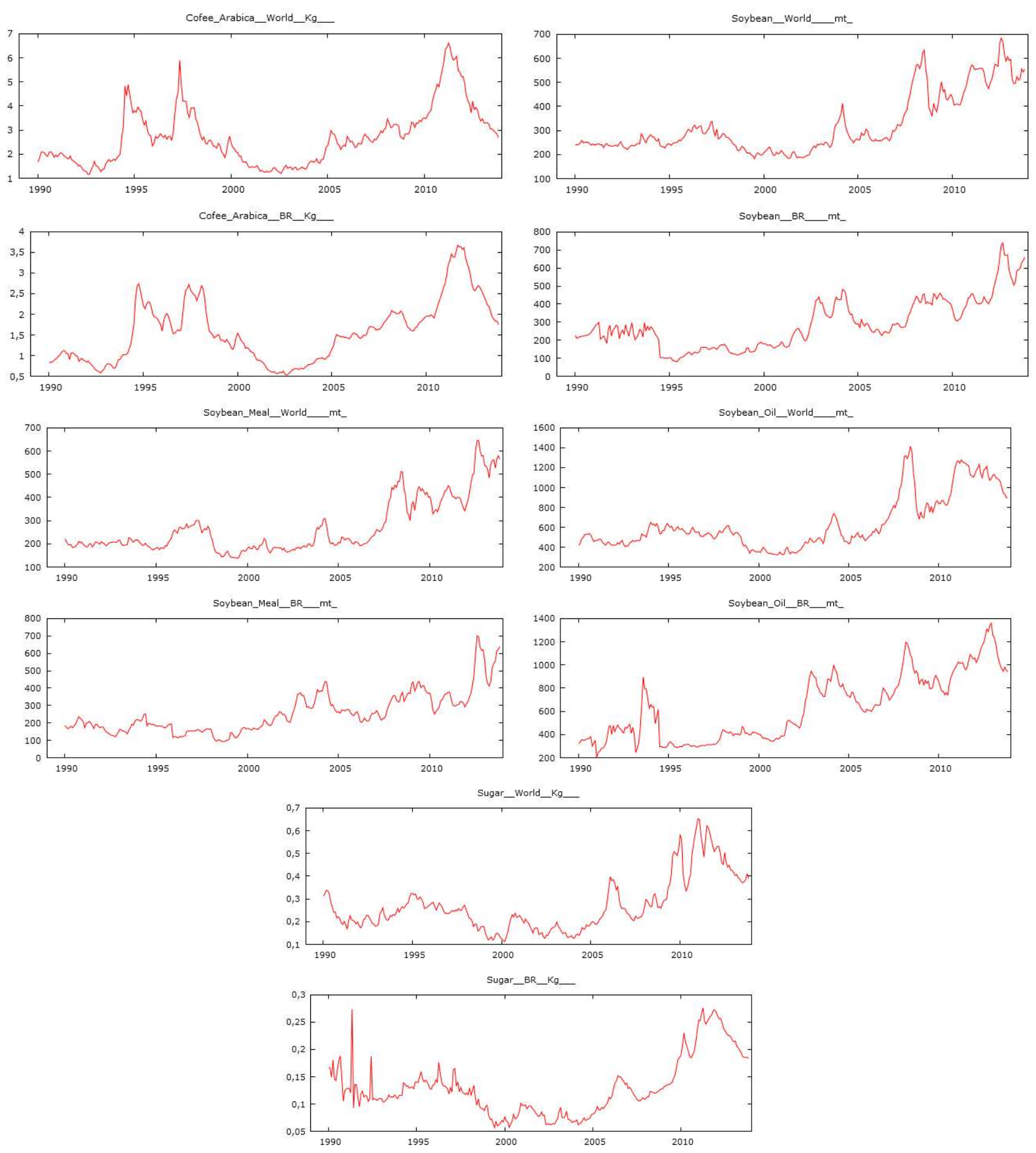

Figura 1: Série de preços das commodities analisadas.

Nota: As séries seguem, respectivamente: Café arábica, soja em grão, farelo de soja, óleo de soja e açúcar, sendo Mundo acima e Brasil abaixo.

Como a maioria dos valores de preço não são estacionários em nível até 5\%, aplicou-se a diferença logarítmica dos preços (função retorno) para que se tenham os valores estacionários. A Tabela 3 a seguir apresenta os valores do teste de raiz unitária para o retorno das commodities.

Tabela 3: Teste de raiz unitária da série de retornos.

\begin{tabular}{lll}
\hline Variáveis & Estatística t & p-valor \\
\hline Café arábica Brasil & $-8,199$ & $\mathbf{0 , 0 0 0}$ \\
Café arábica Mundo & $-9,436$ & $\mathbf{0 , 0 0 0}$ \\
Soja em grão Brasil & $-14,033$ & $\mathbf{0 , 0 0 0}$ \\
Soja em grão Mundo & $-12,719$ & $\mathbf{0 , 0 0 0}$ \\
Farelo de soja Brasil & $-17,895$ & $\mathbf{0 , 0 0 0}$ \\
Farelo de soja Mundo & $-12,645$ & $\mathbf{0 , 0 0 0}$
\end{tabular}




$\begin{array}{lrr}\text { Óleo de soja Brasil } & -13,603 & \mathbf{0 , 0 0 0} \\ \text { Óleo de soja Mundo } & -11,060 & \mathbf{0 , 0 0 0} \\ \text { Açúcar Brasil } & -17,463 & \mathbf{0 , 0 0 0} \\ \text { Açúcar Mundo } & -11,064 & \mathbf{0 , 0 0 0}\end{array}$

Com a técnica de diferença logarítmica da série de preços das commodities chegou-se a todas as séries estacionárias.

\section{Número de defasagens para elaboração da volatilidade}

A seguir, após o procedimento para a chegada à volatilidade das séries, aplicou-se o teste de número de defasagens, através do modelo dos Vetores autorregressivos irrestritos, que também é base para os testes de cointegração. A Tabela 4 a seguir demonstra o número de defasagens para as commodities estudadas.

Tabela 4: Número de defasagens e critérios utilizados.

\begin{tabular}{lllll}
\hline & Defasagens & AIC & BIC & HQC \\
\hline Açúcar & VAR (2) & $-4,704$ & $-4,566^{*}$ & $-4,642^{*}$ \\
Café Arábica & VAR (1) & $-6,242^{*}$ & $-6,114^{*}$ & $-6,288^{*}$ \\
Farelo de Soja & VAR (2) & $5,711^{*}$ & $5,827^{*}$ & $5,771^{*}$ \\
Óleo de soja & VAR (1) & $-5,153$ & $-5,075^{*}$ & $-5,129^{*}$ \\
Soja em grão & VAR (1) & $-5,297$ & $-5,279^{*}$ & $-5,253^{*}$ \\
\hline
\end{tabular}

Nota: *Critério estatística de percimônia atendido.

Para a seleção das defasagens para o modelo, considerando como variáveis exógenas, tanto açúcar do Brasil quanto açúcar Mundo, os critérios de Schwarz e de Hannan-Quinn foram atendidos por questão de percimônia. Para tal, utilizou-se o número de defasagens de 2 para a commodity açúcar. Para a seleção das defasagens para o modelo, considerando como variáveis exógenas, tanto café arábica do Brasil quanto café arábica Mundo, os critérios de Schwarz e de Hannan-Quinn indicaram o número de defasagem de 1 para esta commodity.

Para a seleção das defasagens para o modelo, considerando como variáveis exógenas, tanto farelo de soja do Brasil quanto farelo de soja Mundo, os critérios de Schwarz e de Hannan-Quinn indicaram o número de defasagens de 2 para esta commodity.

Para a seleção das defasagens para o modelo, considerando como variáveis exógenas, tanto Óleo de soja do Brasil quanto Óleo de soja Mundo, os critérios de Schwarz e de Hannan-Quinn foram atendidos por questão de percimônia. Para tal, utilizou-se o número de defasagem de 1 para a commodity óleo de soja.

Para a seleção das defasagens para o modelo, considerando como variáveis exógenas, tanto a soja em grão do Brasil quanto soja em grão Mundo, os critérios de Schwarz e de Hannan-Quinn foram atendidos por questão de percimônia. Para tal, utilizou-se o número de defasagem de 1 para a commodity soja em grão.

\section{Volatilidade}

Com as seleções de defasagens estipulada para cada grupo de commodity par a par, o próximo passo da análise é selecionar o modelo de volatilidade prevista para cada qual. Os modelos de volatilidade escolhidos foram: GARCH, GJR e EGARCH. A Tabela 5 a seguir indica a qualidade de ajustamento do melhor modelo de volatilidade entre os propostos para todas as commodities estudadas, tanto da série mundial 
quanto da série brasileira

Tabela 5: Qualidade de ajuste do melhor modelo de volatilidade.

\begin{tabular}{llllll}
\hline Série Mundo & & & & \\
\hline & Modelo Escolhido & Log Verossimilhança & BIC & AIC & HQC \\
Açúcar & EGARCH & $352,508^{*}$ & $-654,169$ & $-687,006^{*}$ & $-673,803^{*}$ \\
Café Arábica & GJR & $369,088^{*}$ & $-692,825^{*}$ & $-722,077^{*}$ & $-710,323^{*}$ \\
Farelo de Soja & GARCH & $434,431^{*}$ & $-823,683^{*}$ & $-852,862^{*}$ & $-841,104^{*}$ \\
Óleo de soja & GARCH & $441,562^{*}$ & $-843,581^{*}$ & $-869,123^{*}$ & $-858,879^{*}$ \\
Soja em grão & GARCH & 469,254 & $-898,966^{*}$ & $-924,508$ & $-914,374^{*}$ \\
\hline Série Brasil & & & & & \\
\hline & Modelo Escolhido & Log Verossimilhança & BIC & AIC & HQC \\
Açúcar & EGARCH & $345,514^{*}$ & $-640,131^{*}$ & $-673,008^{*}$ & $-659,865^{*}$ \\
Café Arábica & GJR & $484,127^{*}$ & $-923,033^{*}$ & $-952,255^{*}$ & $-940,531^{*}$ \\
Farelo de Soja & EGARCH & $-1208,424$ & $2467,718^{*}$ & $2434,847^{*}$ & $2448,020^{*}$ \\
Óleo de soja & GARCH & $413,295^{*}$ & $-787,028^{*}$ & $-812,581^{*}$ & $-802,340^{*}$ \\
Soja em grão & GARCH & 351,964 & $-664,367^{*}$ & $-689,939$ & $-679,685^{*}$ \\
\hline
\end{tabular}

Nota: * Critério estatístico de percimônia atendido.

Dentre os modelos estipulados para a análise, para a commodity açúcar Mundo, o modelo escolhido foi o EGARCH, na medida que os critérios de Logaritmo de Verossimilhança, Akaike e Hannan-Quinn indicaram EGARCH, e apenas o critério de Schwarz indicou o modelo GARCH. As séries açúcar Brasil e farelo de soja também tiveram como modelo melhor ajustado o EGARCH.

Considerando a commodity café arábica Mundo, o modelo escolhido foi o GJR, assim como ocorrido na série café arábica brasileira. Por fim, as séries farelo de soja, óleo de soja e soja em grão mundiais, assim como o óleo de soja e soja em grão brasileira tiveram o modelo GARCH como melhor ajustado às séries de retornos. Definidos os modelos de volatilidade, faz-se pertinente observar a diferença de incidência de volatilidade de cada commodity tanto dos retornos do mundo, quanto dos do Brasil. A Figura 2 a seguir ilustra as volatilidades das cinco commodities do mundo, e suas diferenças
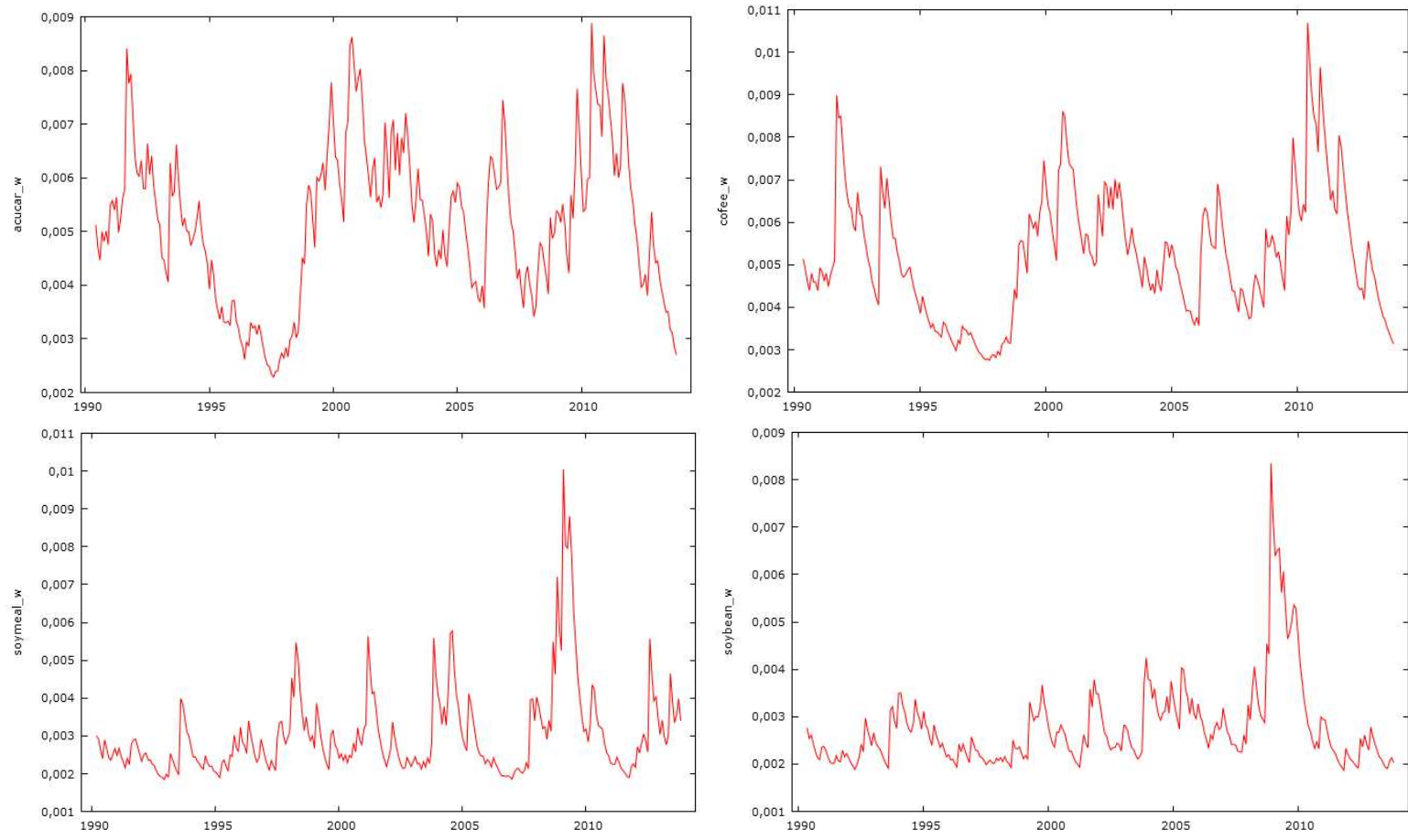


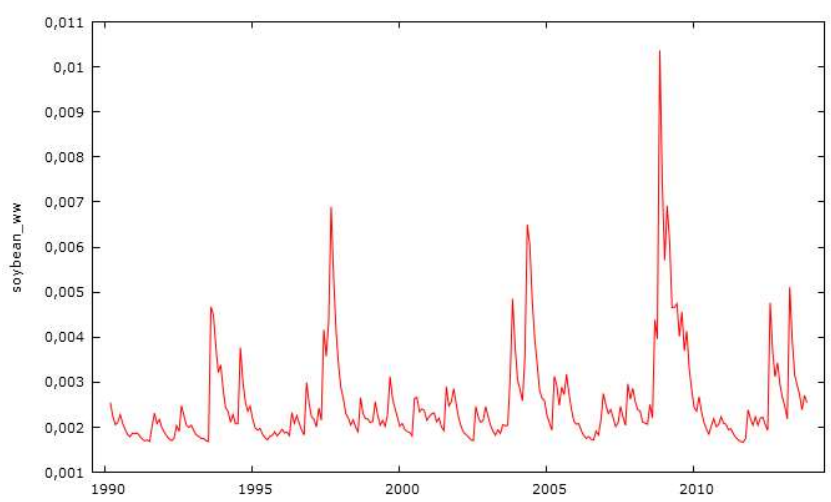

Figura 2: Volatilidades das commodities entre 1990 e 2014: Série Mundo.

Nota: As imagens seguem, respectivamente: açúcar, café arábica, farelo de soja, óleo de soja e soja em grão.

Observa-se, através do Figura 2, que as volatilidades incidentes sobre as variáveis do complexo soja têm mais variação e picos de alta do que aqueles presentes no açúcar e no café. Percebe-se, também, que a volatilidade mais aguda é presente no café arábica, e a menos aguda, no açúcar. Outro ponto interessante de se observar é que, dos produtos que compõem o complexo soja, o de menor volatilidade associada é o óleo de soja.

Outro ponto relevante é que, a volatilidade da série de Açúcar não apresenta muitos picos, comparada às outras commodities, o que pode ser explicado por seu mercado, que não apresenta muitas alterações de demanda. A Tabela 6 a seguir apresenta as estatísticas descritivas das volatilidades da série Mundo

Tabela 6: Estatísticas descritivas volatilidades Série Mundo.

\begin{tabular}{llllll}
\hline & Açúcar & Café & Farelo de Soja & Óleo de Soja & Soja em grão \\
\hline Média & 0,001 & 0,002 & 0,004 & 0,002 & 0,004 \\
Mediana & 0,059 & 0,007 & 0,003 & 0,003 & 0,006 \\
Mínimo & 0,005 & 0,006 & 0,004 & 0,007 & 0,006 \\
Máximo & 0,004 & 0,057 & 0,016 & 0,007 & 0,014 \\
Curtose & 0,053 & 7,774 & 9,046 & 7,889 & 8,276 \\
\hline
\end{tabular}

As estatísticas descritivas corroboram a análise gráfica supracitada. Nota-se que o café arábica teve a maior média de volatilidade durante os períodos analisados, assim como o maior pico de volatilidade. Notase que o açúcar teve as menores incidências de alterações de volatilidade, devido à sua baixa curtose. Observando os valores de mínimo, nota-se que o farelo de soja foi aquele que teve o menor valor de volatilidade dos períodos. Para observar as incidências de volatilidade sobre as commodities da série brasileira, elaborou-se a Figura 3 a seguir.
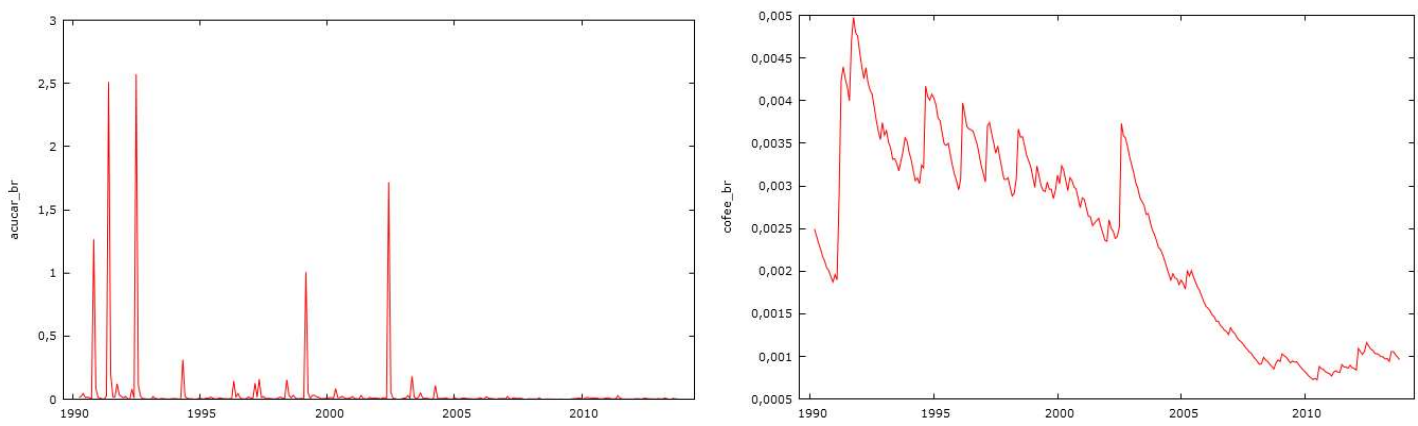


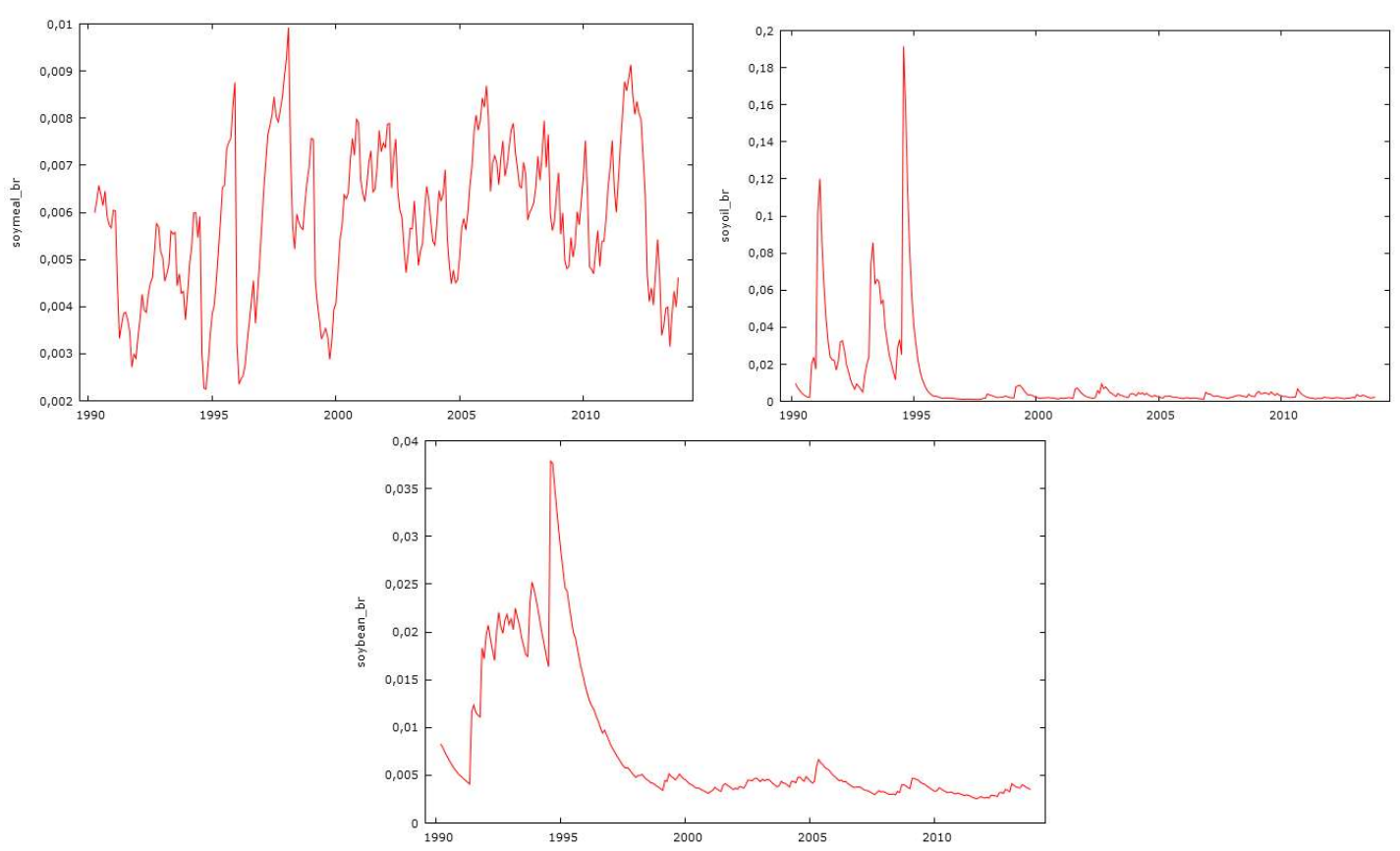

Figura 3: Volatilidades das commodities entre 1990 e 2014 - Série Brasil.

Nota: As imagens seguem, respectivamente: açúcar, café arábica, farelo de soja, óleo de soja e soja em grão.

Observa-se, a partir do Gráfico 2, que o Açúcar é aquele que apresenta maiores picos de volatilidade. Observa-se que uma das diferenças na série brasileira e mundial é que os picos de volatilidade das séries estudadas estão presentes no início do período, até meados dos anos 1999. O que pode explicar este panorama é a última crise financeira brasileira do período FHC, que segundo Oliveira et al. (2003), teve desvalorização cambial a um ritmo relativamente estável, porém insuficiente para a redução do desequilíbrio do mercado em relação ao câmbio real de equilíbrio, gerando a desvalorização do real e a alteração forte dos preços que, por fim, gera volatilidade e flutuações no mercado. A Tabela 7 a seguir contém as estatísticas descritivas da série brasileira, que servirá de auxiliar para a análise gráfica elaborada anteriormente.

Tabela 7: Estatísticas descritivas das commodities - Série Brasil.

\begin{tabular}{llllll}
\hline & Açúcar & Café & Farelo de Soja & Óleo de Soja & Soja em grão \\
\hline Média & 0,014 & 0,002 & 0,007 & 0,002 & 0,009 \\
Mediana & 0,006 & 0,002 & 0,004 & 0,002 & 0,005 \\
Mínimo & 0,000 & 0,000 & 0,000 & 0,001 & 0,003 \\
Máximo & 0,331 & 0,004 & 0,463 & 0,007 & 0,081 \\
Curtose & 4,547 & $-1,296$ & 0,488 & 7,889 & 2,725 \\
\hline
\end{tabular}

Conforme, as estatísticas descritivas, é possível afirmar que a commodity brasileira com maior volatilidade é a do açúcar, visto sua média ser maior do que as demais séries. Observando o valor máximo, nota-se que a commodity que teve maior pico de volatilidade foi o farelo de soja, o que também justifica sua elevada curtose.

As séries de menor volatilidade média no decorrer dos anos foram a de óleo de soja e de café, este último sendo o que de menor alteração de volatilidade, visto que seu valor de curto é bastante baixo. $O$ que se percebe é que, por o Brasil ser um mercado menor que o mercado mundial, e estar sujeito a menos alterações de preços, os valores das volatilidades para o mercado mundial têm mais picos, fonte das flutuações de preços. Nota-se também que para os dois mercados, há diferenças de quem tem maior 
volatilidade, sendo que no brasileiro é a série de açúcar e no mundial a série de Café.

\section{Número de defasagens para a estimação do modelo de vetores autorregressivos}

Definidas as volatilidades e, buscando analisar o comportamento de curto prazo das mesmas, procedeu-se para a análise de número de defasagens para preceder ao modelo de vetores autorregressivos. A Tabela 8 a seguir demonstra o número de defasagens necessárias para a commodity Açúcar.

Tabela 8: Ordem de defasagem do modelo VAR - Volatilidades par a par Açúcar.

\begin{tabular}{|c|c|c|c|c|c|}
\hline Lags & Log Verossimilhança & $p($ LR) & AIC & BIC & HQC \\
\hline 1 & 2769,228 & & $-21,255$ & $-21,173$ & $-21,222$ \\
\hline 2 & 3198,947 & 0,000 & $-24,530$ & $-24,393$ & $-24,475$ \\
\hline 3 & 3201,444 & 0,288 & $-24,518$ & $-24,327$ & $-24,441$ \\
\hline 4 & 3203,164 & 0,487 & $-24,501$ & $-24,254$ & $-24,402$ \\
\hline 5 & 3205,354 & 0,356 & $-24,487$ & $-24,186$ & $-24,366$ \\
\hline 6 & 3207,976 & 0,264 & $-24,476$ & $-24,120$ & $-24,333$ \\
\hline 7 & 3216,327 & 0,002 & $-24,510$ & $-24,099$ & $-24,345$ \\
\hline 8 & 3224,497 & 0,002 & $-24,542$ & $-24,076$ & $-24,355$ \\
\hline 9 & 3230,109 & 0,024 & $-24,554$ & $-24,034$ & $-24,345$ \\
\hline 10 & 3247,658 & 0,000 & $-24,658$ & $-24,083$ & $-24,427$ \\
\hline 11 & 3275,977 & 0,000 & $-24,846$ & $-24,216$ & $-24,592$ \\
\hline 12 & 3285,443 & 0,000 & $-24,888$ & $-24,203$ & $-24,612$ \\
\hline 13 & 3286,076 & 0,866 & $-24,862$ & $-24,122$ & $-24,564$ \\
\hline 14 & 3321,310 & 0,000 & $-25,102$ & $-24,308$ & $-24,783$ \\
\hline
\end{tabular}

Nota: Em negrito, o critério estatístico escolhido.

Com base nos critérios do Logaritmo de Verossimilhança, de Akaike e Hannan-Quinn observou-se que, para a commodity açúcar, o número de defasagens necessários é de 14. A Tabela 9 a seguir demonstra o número de defasagens necessário para a commodity Café Arábica.

Tabela 9: Ordem de defasagem do modelo VAR - Volatilidades par a par Café Arábica

\begin{tabular}{llllll}
\hline Lags & Log Verossimilhança & $\mathbf{p ( L R )}$ & AIC & BIC & HQC \\
\hline 1 & 3136,272 & & $-23,986$ & $-23,904$ & $-23,953$ \\
2 & 3160,955 & 0,000 & $-24,145$ & $-\mathbf{2 4 , 0 0 8}$ & $-24,090$ \\
3 & 3169,352 & 0,002 & $-24,178$ & $-23,987$ & $-24,102$ \\
$\mathbf{4}$ & 3177,197 & 0,003 & $-\mathbf{2 4 , 2 0 8}$ & $-23,962$ & $-\mathbf{2 4 , 1 0 9}$ \\
5 & 3180,687 & 0,136 & $-24,204$ & $-23,908$ & $-24,083$ \\
6 & 3183,044 & 0,317 & $-24,191$ & $-23,836$ & $-24,049$ \\
7 & 3184,365 & 0,619 & $-24,171$ & $-23,761$ & $-24,006$ \\
8 & $\mathbf{3 1 8 5 , 4 8 7}$ & 0,690 & $-24,149$ & $-23,68$ & $-23,962$ \\
\hline
\end{tabular}

Nota: Em negrito, o critério estatístico escolhido.

Observando os critérios de Akaike e Hannan-Quinn, a série de café arábica necessitará de 4 defasagens para se adequar ao modelo. A decisão de utilizar as 4 defasagens é por, dos quatro critérios utilizados, dois estarem indicando a presença de 4 defasagens. A Tabela 10 a seguir demonstra os valores dos critérios para a definição das defasagens do variável farelo de soja.

Tabela 10: Ordem de defasagem do modelo VAR - Volatilidades par a par Farelo de Soja.

\begin{tabular}{lllllll}
\hline Lags & Log Verossimilhança & $\mathbf{p ( L R )}$ & AIC & BIC & HQC \\
\hline 1 & $-254,227$ & & 2,001 & 2,083 & 2,034 \\
2 & $-231,478$ & 0,000 & 1,857 & & $\mathbf{1 , 9 9 4}$ & 1,912 \\
3 & $-220,764$ & 0,000 & 1,805 & & 1,997 & 1,882 \\
4 & $-209,365$ & 0,000 & & $\mathbf{1 , 7 4 8}$ & 1,995 & $\mathbf{1 , 8 4 8}$ \\
5 & $-208,834$ & 0,900 & 1,775 & & 2,076 & 1,896 \\
6 & $-202,639$ & 0,014 & 1,758 & 2,114 & 1,901 \\
\hline
\end{tabular}




\begin{tabular}{llllll}
\hline 7 & $-201,855$ & 0,814 & 1,783 & 2,194 & 1,948 \\
8 & $-194,643$ & 0,006 & 1,758 & 2,224 & 1,945 \\
\hline
\end{tabular}

Nota: Em negrito, o critério estatístico escolhido.

Assim como apresentado no café arábica, o número de defasagens para o farelo de soja foi definido em 4, com base nos critérios de Akaike e Hannan-Quinn, que foram superiores aos de Schwarz, que indicou 2 defasagens e do Logaritmo de Verossimilhança, que indicou 8 defasagens. A Tabela 11 a seguir demonstra os valores dos critérios para definição das defasagens para a commodity Óleo de Soja.

Tabela 11: Ordem de defasagem do modelo VAR - Volatilidades par a par Óleo de Soja.

\begin{tabular}{|c|c|c|c|c|c|}
\hline Lags & Log Verossimilhança & $p$ (LR) & AIC & BIC & HQC \\
\hline 1 & 2436,484 & & 17,548 & $-17,470$ & $-17,517$ \\
\hline 2 & 2438,031 & 0,54206 & $-17,530$ & $-17,400$ & $-17,478$ \\
\hline 3 & 2440,704 & 0,25367 & $-17,521$ & $-17,338$ & $-17,447$ \\
\hline 4 & 2442,665 & 0,41652 & $-17,506$ & $-17,271$ & $-17,412$ \\
\hline 5 & 2444,238 & 0,53635 & $-17,489$ & $-17,201$ & $-17,373$ \\
\hline 6 & 2444,743 & 0,90584 & $-17,463$ & $-17,123$ & $-17,327$ \\
\hline 7 & 2446,006 & 0,64002 & $-17,444$ & $-17,051$ & $-17,286$ \\
\hline 8 & 2447,213 & 0,66006 & $-17,423$ & $-16,979$ & $-17,245$ \\
\hline
\end{tabular}

Nota: Em negrito, o critério estatístico escolhido.

Para a commodity óleo de soja, os critérios de Akaike, Schwarz e Hannan-Quinn indicaram que o número de defasagens ideal é de 1 . Apenas o Logaritmo de Verossimilhança apontou para o número de defasagens de 8 , porém atendeu-se ao maior número de critérios. A Tabela 12 a seguir demonstra os valores dos critérios para definição do número de defasagens necessários para a commodity soja em grão. Assim como acontecido com o óleo de soja, a soja em grão, com os critérios de Akaike, Schwarz e Hannan-Quinn, o número de defasagens a ser abordado é de 1.

Tabela 12: Ordem de defasagem do modelo VAR - Volatilidades par a par Soja em grão.

\begin{tabular}{lllclr}
\hline Lags & Log Verossimilhança & $\mathbf{p}($ LR) & AIC & BIC & HQC \\
\hline $\mathbf{1}$ & 2562,428 & & $-\mathbf{1 9 , 5 8 9}$ & $\mathbf{- 1 9 , 5 0 7}$ & $\mathbf{- 1 9 , 5 5 6}$ \\
2 & 2563,405 & 0,7449 & $-19,566$ & $-19,429$ & $-19,511$ \\
3 & 2565,169 & 0,4734 & $-19,549$ & $-19,358$ & $-19,472$ \\
4 & 2568,612 & 0,1423 & $-19,544$ & $-19,299$ & $-19,446$ \\
5 & 2569,914 & 0,6253 & $-19,524$ & $-19,223$ & $-19,403$ \\
6 & 2571,774 & 0,4452 & $-19,507$ & $-19,152$ & $-19,365$ \\
7 & 2575,089 & 0,1567 & $-19,502$ & $-19,092$ & $-19,337$ \\
8 & $\mathbf{2 5 7 6 , 9 2 1}$ & 0,4533 & $-19,486$ & $-19,021$ & $-19,299$ \\
\hline
\end{tabular}

Nota: Em negrito, o critério estatístico escolhido.

\section{Comportamento de curto prazo}

Para avaliar o comportamento de cada commodity par a par, Brasil em relação ao mundo e viceversa, fez-se uso do modelo de vetores autorregressivos, que indica a dependência de uma variável defasada consigo mesma, além da dependência desta mesma variável com outra defasada. A Tabela 13 a seguir demonstra o comportamento da commodity açúcar.

Inicialmente, tomando a variável Açúcar Mundo como dependente, nota-se que sua volatilidade está associada com ela mesma, com 1, 2 e 7 defasagens, o que indica a persistência da volatilidade aos seus próprios choques. Também, faz-se relevante analisar que a volatilidade do açúcar mundial é afetada pela volatilidade do açúcar brasileiro, com até 12 defasagens, o que indica que o mercado mundial pode estar 
associado sazonalmente com o mercado brasileiro, visto que a $12^{a}$ defasagem indica, a princípio, o mesmo mês no ano anterior.

Tabela 13: Autorregressão Vetorial - Açúcar.

\begin{tabular}{llccc}
\hline \multicolumn{2}{l}{ Variável Dependente: Açúcar_Mundo } & & & \\
\hline & Coeficiente & Erro padrão & Razão t & p-valor \\
constante & 0,000 & 0,000 & 4,194 & 0,000 \\
Açucar_Mundo_1 & 2,044 & 0,064 & 31,670 & 0,000 \\
Açucar_Mundo_2 & $-1,093$ & 0,146 & $-7,452$ & 0,000 \\
Açucar_Mundo_7 & $-0,330$ & 0,155 & $-2,126$ & 0,034 \\
Açucar_Brasil_1 & 0,000 & 0,000 & 3,295 & 0,001 \\
Açucar_Brasil_2 & $-0,000$ & 0,000 & $-2,263$ & 0,024 \\
Açucar_Brasil_11 & 0,000 & 0,000 & 2,505 & 0,012 \\
Açucar_Brasil_12 & $-0,000$ & 0,000 & $-2,414$ & 0,016 \\
\hline Variável Dependente: Açúcar_Brasil & & & \\
\hline constante & 0,004 & 0,007 & 0,581 & 0,561 \\
Açucar_Brasil_1 & 1,104 & 0,063 & 17,468 & 0.000 \\
Açucar_Brasil_2 & $-0,193$ & 0,094 & $-2,048$ & 0,042 \\
Açucar_Brasil_3 & $-0,386$ & $-4,017$ & 0,000 \\
Açucar_Brasil_4 & 0,385 & 0,096 & 3,873 & 0,000 \\
Açucar_Brasil_14 & $-0,198$ & 0,065 & $-3,026$ & 0,002 \\
\hline
\end{tabular}

Nota: Apenas foram incluídas as variáveis que apresentaram grau de significância de 5\%; O número após "_" indica o número de defasagens da série.

Tomando a variável Açúcar Brasil como dependente, nota-se que a sua volatilidade está somente associada com ela mesma, com 1, 2, 3, 4 e 14 defasagens, não sendo afetada pela volatilidade mundial, isto é, com volatilidade unidirecional. Este quadro indica que o mercado de açúcar brasileiro é sazonal, visto que a sua volatilidade tem dependência com 3 e 14 defasagens, indicando que o terceiro mês têm implicância no terceiro mês do ano anterior.

Isso pode ser explicado pelo fato de que, segundo a Faostat (FAO, 2013), o Brasil tem aumentado sua importância no mercado de açúcar mundial devido às manobras de aumento de preço, sendo estas possibilitadas porque a produção da cana-de-açúcar está sendo subsidiada no país. Para avaliar o comportamento da variável café, a Tabela 14 a seguir demonstra os valores da autorregressão vetorial.

Tabela 14: Autorregressão Vetorial - Café Arábica.

\begin{tabular}{|c|c|c|c|c|}
\hline \multicolumn{5}{|c|}{ Variável dependente: Café_Mundo } \\
\hline & Coeficiente & Erro padrão & Razão t & p-valor \\
\hline constante & 0,001 & 0,000 & 3,216 & 0,001 \\
\hline Café_Mundo_1 & 0,485 & 0,059 & 8,117 & 0,000 \\
\hline Café_Mundo_2 & 0,406 & 0,069 & 5,811 & 0,000 \\
\hline Café_Mundo_3 & $-0,131$ & 0,072 & $-1,814$ & 0,070 \\
\hline Café_Mundo_4 & $-0,193$ & 0,064 & $-2,992$ & 0,003 \\
\hline \multicolumn{5}{|c|}{ Variável dependente: Café_BR } \\
\hline constante & 0,000 & 0,000 & $-0,703$ & 0,482 \\
\hline Café_Mundo_1 & 0,020 & 0,002 & 7,026 & 0,000 \\
\hline Cafè_Mundo_2 & $-0,012$ & 0,003 & $-3,677$ & 0,000 \\
\hline Café_Brasil_1 & 1,100 & 0,060 & 18,114 & 0,000 \\
\hline Café_Brasil_2 & $-0,184$ & 0,090 & $-2,043$ & 0,042 \\
\hline
\end{tabular}

*Nota: Apenas foram incluídas as variáveis que apresentaram grau de significância de 5\%; 0 número após "_" indica o número de defasagens da série.

Diferentemente do quadro do açúcar, nota-se que, ao tomarmos como variável dependente o café mundo, observa-se que há volatilidade unidirecional, isto é, que a volatilidade dos retornos do café brasileiro não influi diretamente na volatilidade do café mundial. Isto pode ser explicado pela grande gama de 
produtores de café no mundo - cerca de 72 países- e porque a produção desta commodity está diretamente associada ao fator climático dos trópicos de Câncer e Capricórnio, o que pulveriza mais o mercado mundial de café.

Avaliando a variável café Brasil como dependente, nota-se que a volatilidade do Brasil está associada com ela mesma, com 2 defasagens, indicando que influência da volatilidade percorre 2 meses. Assim como a volatilidade do Brasil depende dela mesma, a mundial influi na brasileira também com 2 defasagens. Este último fato pode ser explicado pela alta gama de países presentes no mercado de café no mundo, o que determina muitas vezes os preços dentro do país. A Tabela 15 a seguir demonstra o comportamento das volatilidades do Farelo de Soja.

Tabela 15: Autorregressão Vetorial - Farelo de Soja.

\begin{tabular}{lllll}
\hline \multicolumn{2}{l}{ Variável Dependente: Fsoja_Mundo } & & & \\
\hline & Coeficiente & Erro padrão & Razão t & p-valor \\
constante & 0,000 & 0,000 & 4,147 & 0.000 \\
Fsoja_Mundo_1 & 0,736 & 0,063 & 11,533 & 0,000 \\
Fsoja_Mundo_3 & 0,205 & 0,078 & 2,615 & 0,009 \\
Fsoja_Mundo_4 & $-0,205$ & 0,064 & $-3,192$ & 0,001 \\
\hline Variável Dependente: Fsoja_Brasil & & & 0,020 \\
\hline Fsoja_Mundo_2 & $-0,580$ & 0,248 & $-2,333$ & 0,003 \\
Fsoja_Mundo_3 & 0,746 & 0,248 & 2,997 & 0,000 \\
Fsoja_Brasil_1 & 1,348 & 0,064 & 20,847 & 0,000 \\
Fsoja_Brasil_2 & $-0,723$ & 0,108 & $-6,669$ & 0,000 \\
Fsoja_Brasil_3 & 0,482 & 0,106 & 4,541 & 0,001 \\
Fsoja_Brasil_4 & $-0,206$ & 0,064 & $-3,223$ & \\
\hline
\end{tabular}

*Nota: Apenas foram incluídas as variáveis que apresentaram grau de significância de 5\%; 0 número após “_" indica o número de defasagens da série.

Assim como acontecido com o café, o mercado de farelo de soja mundial tem volatilidade unidirecional, isto é, apenas é afetado por ele mesmo, que neste caso é com 1, 3 e 4 defasagens. Considerando o farelo de soja Brasil como variável dependente, nota-se que este é afetado pelo mercado mundial em 2 e 3 defasagens. Considerando os efeitos da volatilidade do próprio mercado brasileiro, notase uma persistência desta, que percorre até 4 defasagens. Este fato é indicativo de que o mercado de farelo de soja brasileiro tem persistência de volatilidade presente, o que faz com que um distúrbio de preços possa perdurar até 4 meses, tornando este mercado bastante instável para quem investe. A Tabela 16 a seguir demonstra o comportamento da volatilidade do Óleo de Soja.

Tabela 16: Autorregressão Vetorial - Óleo de Soja.

\begin{tabular}{lllcl}
\hline \multicolumn{2}{l}{ Variável Dependente: Osoja_Mundo } & & & \\
\hline & Coeficiente & erro padrão & Razão t & p-valor \\
constante & 0,000 & 0,000 & 3,545 & 0,000 \\
Osoja_Mundo_1 & 0,000 & 0,025 & 35,784 & 0,000 \\
\hline Variável Dependente: Osoja_Brasil & 0,000 & & & \\
\hline Osoja_Brasil_1 & 0,046 & 13,761 & 0,000 \\
\hline
\end{tabular}

*Nota: Apenas foram incluídas as variáveis que apresentaram grau de significância de 5\%; O número após "_" indica o número de defasagens da série.

Diferentemente dos outros mercados analisados, o óleo de soja tem apenas volatilidade unidirecional, tanto se for considerado como variável dependente o Brasil quanto o mundo, e com comportamento presente em apenas 1 defasagem. $O$ que se pode concluir do mercado de óleo de soja é 
que, dentre os analisados até aqui, é aquele que apresenta menos variações e dependências com outros mercados, se tornando um mercado de pouca persistência de volatilidade. A Tabela 17 a seguir demonstra o comportamento da volatilidade da variável Soja em grão.

Tabela 17: Autorregressão Vetorial - Soja em Grão.

\begin{tabular}{lllcl}
\hline \multicolumn{2}{l}{ Variável Dependente: Gsoja_Mundo } & & & \\
\hline & Coeficiente & erro padrão & Razão t & p-valor \\
const. & 0,000 & 0,000 & 4,685 & 0,000 \\
Gsoja_Mundo_1 & 0,000 & 0,032 & 26,221 & 0,000 \\
\hline Variável Dependente: Gsoja_BR & & & & \\
\hline Gsoja_BR_1 & 0,000 & 0,028 & 31,452 & 0,000 \\
\hline
\end{tabular}

*Nota: Apenas foram incluídas as variáveis que apresentaram grau de significância de 5\%; 0 número após “_" indica o número de defasagens da série.

Assim como o mercado de óleo de soja, o mercado de soja em grão apresenta volatilidade unidirecional para ambos, tanto Brasil quanto mundo, isto é, a volatilidade do grão de soja mundo é apenas afetada por ela mesma, assim como a volatilidade do mercado de grado de soja brasileiro. Este fenômeno pode ter explicação pela crescente participação da soja em grão na pauta brasileira de exportações, o que faz com que este mercado seja um grande definidor de preços, que faz seus movimentos de volatilidade sejam afetados apenas por ele mesmo.

Com relação ao mercado mundial, o que pode explicar a volatilidade unidirecional é que a participação do mercado americano sobre o mundo, com imposições tarifárias de alterações de oferta e demanda, faz com que se imagine que a volatilidade do mercado mundial de soja em grão seja influenciada pelo mercado americano.

\section{CONCLUSÕES}

O mercado de commodities agrícolas tem papel determinante nas pautas de exportações dos países, especialmente os em desenvolvimento, devendo o seu baixo valor de produção à crescente demanda por estes produtos, especialmente pelo mercado chinês. $O$ crescimento deste mercado faz com que os preços estejam expostos às variações de ordem política, econômica, de demanda e oferta, além das variações climáticas e sazonais que este mercado sofre, o que faz com que as flutuações de preços sejam mais evidentes.

É sob esta justificativa que o trabalho se fez presente, para analisar o contexto brasileiro de volatilidade de commodities agrícolas frente ao mundo, para buscar entendimento das variações destes preços. Notou-se que, para o mercado mundial, a commodity com maior incidência de volatilidade foi o café, já no Brasil, foi o açúcar, o que a priori já se esperava, visto que estes dois passam por um ciclo produtivo.

Analisando o comportamento de curto prazo das volatilidades, observou-se que para café, açúcar e farelo de soja, o Brasil tem influência com certa persistência de volatilidade do restante do mundo, determinando que os movimentos dos preços destes últimos sejam atrelados à realidade mundial, e sendo mais difícil de prever e de tomar decisões para modificar tal panorama.

O mercado de óleo de soja e soja em grão apresentou volatilidade unidirecional, ou seja, para o 
contexto brasileiro, a volatilidade do mundo não afeta os preços destas commodities, o que pode ser explicado pelo tamanho do mercado brasileiro de soja, sendo este aferidor de preços, o que faz com que suas próprias ações façam com que haja flutuações nos preços.

Para futuros trabalhos, sugere-se a inclusão de outros mercados de commodities, tais quais o americano, o chinês e o da União Europeia, a fim de avaliar a presença de influência das volatilidades destes mercados no brasileiro e mundial. Por fim, observa-se que este trabalho pode ser de grande utilidade para produtores e hedgers, na medida em que fornece informações dos riscos de cada mercado, e a influência mundial acerca do mercado brasileiro.

\section{REFERÊNCIAS}

BALTAGI, B. H.. Econometric Analysis of Panel Data. 3 ed. Chichester: John Wiley \& Sons, 2005.

BOVESPA. Bolsa de mercadorias e futuros de São Paulo. Índice de commodities Brasil. São Paulo: BOVESPA, 2014.

BRANCO, A. L. O. C.. A produção de soja no Brasil: uma análise econométrica no período de 1994-2008. Monografia (Bacharelado em Ciências Econômicas) - Pontifícia Universidade de Campinas, São Paulo, 2008.

BOLLERSLEV, T.. Generalized Autoregressive Conditional Heteroscedasticity. Journal of Econometrics, v.31, p.307-27, 1986. DOI: http://doi.org/10.1016/0304-4076(86)90063-1

BUENO, R. L. S.. Econometria de séries temporais. São Paulo: Cengage Learning, 2008

CAMPOS, K. C.. Análise da volatilidade de preços de produtos agropecuários no Brasil. Revista de Economia e Agronegócio, v.5, n.3, p.303-328, 2007.

CEPEA. Centro de Estudos Avançados em Economia Aplicada. Açúcar: um informativo quinzenal. CEPEA, 2012.

FAO. Organização para a Alimentação e Agricultura das Nações Unidas. Brasil é a maior influência do mercado de açúcar mundial. FAO, 2013.

FAVA, V. L.; CATI, R. C.. Mudanças no comportamento do PIB brasileiro: uma abordagem econométrica. Pesquisa e planejamento econômico, Rio de Janeiro, v.25, n.2, p.279 296, 1995.

GIL, A. C.. Como elaborar projetos de pesquisa. 4 ed. São Paulo: Atlas, 2002

GLOSTEN, L. R.; JAGANNATHAN, R.; RUNKLE, D. E.. On the Relation between Expected Value and the Volatility of the Nominal Excess Return on Stocks. Journal of Finance, v.48, p.1779-1801. DOI: http://doi.org/10.1111/j.15406261.1993.tb05128.x

LEROY, F. L. D.; SANTOS, J. M.. Será possível um crescimento regional independente? Uma abordagem utilizando vetores autorregressivos. 2008.

PEREIRA, V. F.; LIMA, J. E.; BRAGA, M. J.; MENDONÇA, T. G.. Volatilidade dos retornos de commodities agropecuárias brasileiras. Revista de Economia, v.36, n.3, p.73-94, 2010.

RAMPAZZO, L.. Metodologia científica: para alunos dos cursos de graduação e pós-graduação. São Paulo: Loyola, 2002.

MARGARIDO, M. A.; BUENO, C. R. F.; MARTINS, V. A.; CARNEVALLI, L. B.. Análise dos efeitos de preços e câmbio sobre o preço do óleo de soja na cidade de São Paulo: Uma aplicação do modelo VAR. Pesquisa \& Debate, São Paulo, v.15, n.1, p.69-106, 2004

MORAIS, I. A. C.; PORTUGAL, M. S.. Modelagem e previsão de volatilidade determinística e estocástica para a série do Ibovespa. Porto Alegre: UFRGS 1999.

NELSON, D. B.. Conditional Heteroscedasticity in Asset Returns: A New Approach. Econométrica, v.59, p.347-70, 1991. DOI: http://doi.org/10.2307/2938260

NG, S.; PERRON, P.. Lag Length selection and the construction of unit root testes with good size and power Econometrica, v.69, n.6, 2001. DOI: http://doi.org/10.1111/1468-0262.00256

OLIVEIRA, G.; TUROLLA, F.. Política econômica do segundo governo FHC: mudança em condições adversas. Tempo Social, v.15, n.2, São Paulo, 2003. DOI: http://doi.org/10.1590/S0103-20702003000200008

SILVA, W. S.; SAFADI, T.; CASTRO JÚNIOR, L. G.. Uma análise empírica da volatilidade do retorno de commodities agrícolas utilizando modelo ARCH: os casos do café e da soja. Revista de Sociologia Rural, v.43, n.1, p.119-134, 2005. DOI: http://doi.org/10.1590/S0103-20032005000100007

SWARAY, R. B.. Volatility on primary commodity prices: some evidence from agricultural exports in Sub-Saharan Africa. University of York, 2002

TEIXEIRA, G. S.; MAIA, S. F.; FIGUEIREDO, N. M.; PEREIRA, E. S.; PINTO, P. A. L. A.. Dinâmica da volatilidade do retorno das principais commodities brasileiras: uma abordagem dos modelos ARCH. In: CONGRESSO DA SOBER, 46. Anais. Rio Branco, 2008.

TEIXEIRA, W. S.. Cana-de-açúcar: prospecções para a safra de 2013/2014. 2014

A CBPC - Companhia Brasileira de Produção Científica (CNPJ: 11.221.422/0001-03) detém os direitos materiais desta publicação. Os direitos referem-se à publicação do trabalho em qualquer parte do mundo, incluindo os direitos às renovações, expansões e disseminações da contribuição, bem como outros direitos subsidiários. Todos os trabalhos publicados eletronicamente poderão posteriormente ser publicados em coletâneas impressas sob coordenação da Sustenere Publishing, da Companhia Brasileira de Produção Científica e seus parceiros autorizados. Os (as) autores (as) posteriormente ser publicados em coletâneas impressas sob coordenação da Sustenere Publishing, da Companhia Brasileira de Produção Cientifica e seus parce 